\title{
И.В. Чаднова
}

\section{Межкультурный диалог в библиотеках: теоретические и практические аспекты}

Реферат. Современные общедоступные библиотеки страны вовлечены в работу по реализации государственной культурной и национальной политики. В последнее время в центре их приоритетных задач - обеспечение межнационального согласия в обществе, понимаемое библиотеками как работа, направленная на развитие межкультурного диалога. В статье освещаются теоретические и практические аспекты развития межкультурного диалога в общедоступных библиотеках. Дается определение межкультурного диалога как процесса, имеющего своей целью открытое и вежливое общение между различными народами, основанного на взаимном понимании и уважении. Деятельность библиотеки может способствовать воспитанию навыков и созданию пространства для его расширения. Автор показывает, что основа современной межкультурной деятельности библиотек была заложена работой советских массовых библиотек по изучению читательских интересов народов многонационального СССР и участию в их интернациональном воспитании. В настоящее время библиотеки способствуют развитию национального образования титульных этносов и помогают процессу взаимообогащения культур разных народов нашей страны в соответствии с «Основами государственной культурной политики». Теоретическая база межкультурной работы библиотек пополняется за счет диссертационных исследований, защищаемых в различных регионах страны. Это позволяет сделать вывод о том, что в общей структуре современного библиотековедения уже сформировался самостоятельный раздел, получивший название «библиотечная этнология». Для того чтобы стать одним из главных трансляторов культурной и национальной политики государства, общедоступные библиотеки выработали свои подходы, которые выразились в создании центров межнационального взаимодействия и межкультурных коммуникаций, а также центров национальных литератур. Как правило, основной целью их деятельности является создание условий для развития межкультурных и межэтнических отношений у пользователей на основе ценностей многонационального российского общества, соблюдения прав и свобод человека, поддержание межнационального мира и согласия в регионе.

Ключевые слова: межкультурный диалог, общедоступные библиотеки, государственная культурная политика, центр межнационального взаимодействия и национальных литератур, теоретическая база, формы работы библиотек.

Для цитирования: Чаднова И.В. Межкультурный диалог в библиотеках: теоретические и практические аспекты // Библиотековедение. 2017. Т. 66, № 6. С. 636-642. DOI: 10.25281/0869-608X-2017-66-6636-642.

\section{Определение межкультурного диалога}

Современные общедоступные библиотеки страны вовлечены в работу по реализации государственной культурной и национальной политики, развитию межэтнических отношений и гражданского единства российского общества. В последнее время в центр библиотечной работы перемещается тема обеспечения межнационального согласия в обществе и противодействия экстремизму как фактор сохранения российской государственности, понимаемая библиотеками как работа, направленная на развитие межкультурного диалога.

В «Белой книге по межкультурному диалогу» он определяется «как процесс, включающий

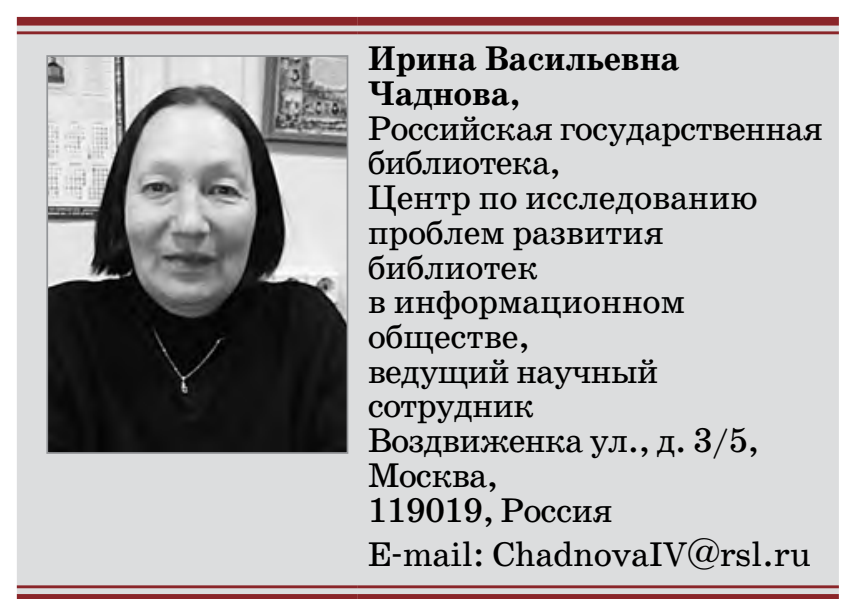


в себя открытый и вежливый обмен мнениями между лицами и группами с различным этническим, культурным, религиозным и языковым прошлым и наследием, основанный на взаимном понимании и уважении. Межкультурный диалог способствует политической, социальной, культурной и экономической интеграции и сплочению поликультурных обществ. Он поощряет равенство, человеческое достоинство и чувство общей цели. Он имеет целью развитие более глубокого понимания различного мировоззрения и поведения, повышения уровня сотрудничества и вовлеченности (или свободу выбора), создание условий для развития личности, а также продвижение толерантности и уважения к другому человеку» [1, с. 17].

Отмечается также, что для успешного продвижения межкультурного диалога в обществе должны быть выполнены следующие предварительные условия:

- преподаваться и воспитываться навыки межкультурного диалога;

- создаваться и расширяться пространство для него;

- межкультурный диалог должен выйти на международный уровень $[1$, с. 4$]$.

Деятельность современной общедоступной библиотеки может способствовать реализации, по крайней мере, двух этих условий:

- воспитанию навыков межкультурного диалога;

- созданию пространства для его расширения.

Определение межкультурного диалога как процесса, имеющего своей целью открытое и вежливое общение между различными народами и основанного на взаимном понимании и уважении, дает нам основание утверждать, что библиотека обладает большим потенциалом для установления этого диалога (тем более в такой поликультурной стране, как Российская Федерация).

\section{Теоретические аспекты межкультурной деятельности библиотек}

Основа современной межкультурной деятельности библиотек была заложена работой советских массовых библиотек по изучению читательских интересов народов многонационального CCCP, тем самым библиотеки участвовали в их интернациональном воспитании.

Начиная с 1950-х гг. проблема изучения читателей и их интересов получает широкое распространение и становится составной частью отечественной библиотечной работы. В масштабах страны началась организация специальных социологических исследований. Изучению проблем общего и национально-особенного в читательских потребностях было посвящено комплексное двухэтапное исследование под названием «Чтение как фактор сближения культур народов СССР», проведенное Государственной библиотекой СССР им. В.И. Ленина (ГБЛ) в качестве всесоюзного научно-методического центра (1978-1984 гг.) [2].

Интернационализация предполагала активное приобщение каждого члена общества к духовному богатству различных народов. В отечественном библиотековедении процесс интернационализации чтения был выявлен и проанализирован Н.Е. Добрыниной. Исследователь подчеркивает, что в активизации процесса интернационализации чтения существенную роль играет массовая библиотека. С самых первых шагов своей истории массовые библиотеки в нашей стране решали две взаимосвязанные задачи: способствовали развитию национальной культуры в республиках и помогали процессу взаимообогащения культур народов СССР. Выступая одним из звеньев разветвленной системы социальных институтов, интернационализирующих жизнь советского народа, массовая библиотека как бы фокусировала их взаимодействие. Значимость ее определялась и тем, что она тесно соприкасалась с процессом сближения национальных культур, имела возможность его наблюдать и корректировать, осуществляя обратную связь и измеряя конечные результаты своего труда [3].

Если говорить о современной работе общедоступных библиотек, то наблюдается следующая закономерность: библиотеки способствуют развитию национальной культуры титульных этносов и помогают процессу взаимообогащения культур разных народов Российской Федерации. В этом видится не только плодотворная традиция работы советских массовых библиотек, но и соответствие общедоступных библиотек современным требованиям, поскольку, согласно «Основам государственной культурной политики» (2014 г.), этнокультурная деятельность библиотек как социально-культурных институтов направлена не только на сохранение этнических культур, но и на их взаимообогащение за счет лучших достижений этносов [4].

Среди теоретических разработок следует назвать исследование Е.Ю. Гениевой, которая назвала библиотеку «центром межкультурной коммуникации» [5]. Она считала, что современная библиотека не только собирает и хранит документы, но и принимает активное участие в социализации читателей, способствует формированию плюралистического видения окружающего их мира и основ толерантного мышления, т. е. несет на себе именно поликультурную коммуникационную функцию. И главным инструментом в реализации данной функции является «постоянный межкультурный тренинг: повышение уровня образования, интеллектуальной, правовой и культурной компетенции, знаний, умений, творческих способностей, поощение индивидуальных склонностей, в конечном счете - самореализацию в течение всей жизни в постоянном контакте с “памятью мира" и в живом общении с себе подобными» [5, с. 80].

Современная теоретическая база работы общедоступных библиотек, направленная на раз- 
витие межкультурного диалога в российском обществе, постоянно пополняется. За последнее десятилетие увеличилось число диссертационных исследований. В условиях поликультурного общества интеграция библиотечной науки с такими дисциплинами, как этнология, этническая психология, этнолингвистика, этнопедагогика и другими неизбежна. В настоящее время можно с уверенностью сказать, что наличие в библиотечной сфере некой «критической массы» [6] научных исследований привело к тому, что в общей структуре современного библиотековедения уже сформировался самостоятельный раздел, получивший название «библиотечная этнология» (этнобиблиотековедение).

Так, на основе анализа содержания авторефератов кандидатских и докторских диссертаций за 2012-2015 гг., защищенных по теме «библиотечная этнология», были выявлены соответствующие работы:

- Например, И.Н. Гудкова исследовала библиотеку полиэтнического региона - Республики Бурятия. Она утверждает, что деятельность библиотеки является своеобразным отображением культурного пространства, сформировавшегося в результате длительного исторического преобразования и сосуществования культур разных народов. Одним из таких регионов и является Республика Бурятия, где проявляется особый интерес к библиотеке. Он обусловлен двумя взаимосвязанными процессами: с одной стороны, усилением глобализации и информатизации современного общества, с другой - развитием процессов локализации и формирования культурного разнообразия. Автор полагает, что в России в ситуации усиливающегося культурного разнообразия, с одной стороны, и стремления сохранить и развивать национально-культурную самобытность - с другой, проблема библиотечного обслуживания полиэтнического населения, вероятно, станет одним из главных направлений исследований. Автор доказал, что глобальные изменения, происходящие в обществе, являются мощными факторами трансформации современной деятельности библиотек, которые способны взять на себя ответственность за обеспечение культурного и информационного единства народов России на всей территории, сохраняя в то же время индивидуальность и неповторимость каждого. На основе разработанного ею проекта (Концепция развития Национальной библиотеки как центра культурного разнообразия и толерантности) были внесены дополнения в такие официальные документы региона, как «Концепция развития библиотечного дела в Республике Бурятия» и «Концепция государственной национальной политики Республики Бурятия» [7].

- Новые подходы к реализации межкультурных коммуникаций в условиях библиотек представлены в работе Л.Х. Сатаровой. Автор доказала, что успешность позиционирования библиотеки как стратегического партнера в обучении различных категорий пользователей межкультурному общению в условиях библиотечного пространства определяется, с одной стороны, наличием гуманистических ресурсов библиотечного института, его ориентацией на воспитание человека в поликультурном пространстве, а с другой - обоснованием условий и процесса реализации обучения межкультурному общению в современной библиотечно-информационной среде. Исследование содержит формы обучения, технологии коммуникативного аудита для диагностики межкультурных коммуникаций в условиях современной библиотеки, а также темы и модели тренингов [8].

- Изучению общедоступной библиотеки как субъекта, участвующего в процессе формирования культуры межнационального взаимодействия, и научном обосновании ее деятельности в условиях возрастания межкультурных контактов и взаимодействий посвящена работа С.В. Кокориной. На основе исследования деятельности общедоступных библиотек Свердловской области автор убедительно показала, что, включаясь в процессы формирования культуры межнационального взаимодействия, общедоступные библиотеки выполняют культурообразующую роль посредством реализации социальных функций, среди которых коммуникативная выступает в качестве доминирующей. Участие библиотек в процессах формирования межнационального взаимодействия делает их равноправными партнерами в реализации национальной политики России [9].

Отметим, что современная теоретическая база пополняется последними законодательными актами. Среди недавно принятых следует назвать новую редакцию Модельного библиотечного кодекса для государств - участников Содружества Независимых Государств (СНГ), в разработке которого участвовали и специалисты Российской государственной библиотеки (РГБ). Кодекс был принят на 45 пленарном заседании Межпарламентской Ассамблеи государств - участников СНГ (ноябрь 2016 г.) и представляет собой систематизированный законодательный акт рекомендательного характера, предназначенный для сближения правового регулирования в сфере библиотечного дела в странах СНГ. Глава 17 Раздела $\mathrm{V}$ касается этнокультурного библиотечного

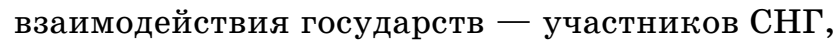
целями которого является содействие библиотечными средствами укреплению межнационального согласия, просвещению, гармоничному развитию национальных культур и духовности общества, проявлению уважительного отношения к культуре и традициям различных этносов, сохранению общего культурного достояния народов евразийского региона [10, с. 58]. 


\section{Практические аспекты работы библиотек как центров по развитию меккультурного диалога}

Для того чтобы стать одним из главных трансляторов культурной и национальной политики государства, общедоступные библиотеки выработали свои подходы в соответствии с самобытностью местного этнокультурного и религиозного ландшафта. Они выразились, прежде всего, в том, что библиотеки предоставили свои площадки для центров межнационального взаимодействия и межкультурных коммуникаций, справедливо полагая, что работа подобных структур открывает хорошие перспективы для привлечения читателей в библиотеку и создания уникальной поликультурной и информационной среды на отдельной территории. Их деятельность способствует также гармонизации межнациональных и межконфессиональных отношений, соблюдению прав и свобод человека, поддержанию межнационального мира и согласия в регионе.

Открылись такие центры, как:

- Информационно-библиотечный Центр межнационального общения "Диалог» в Ставропольской краевой УНБ им. М.Ю. Лермонтова (создан в 2012 г.);

- Центр этнокультурного диалога на базе отдела литературы на языках народов мира Государственной универсальной научной библиотеки Красноярского края (создан в 2013 г.);

- Центр межкультурных коммуникаций на базе отдела литературы на иностранных языках в Волгоградской ОУНБ им. А.М. Горького (создан в 2014 г.);

- Центр национальной культуры и межэтнической толерантности «Под одним небом» в Центральной городской библиотеке им. А.М. Горького Арзамаса (создан в 2014 г.);

- Городской межнациональный центр Новосибирска на базе Центра национальных литератур (создан в 2014 г.).

Как правило, главной целью их деятельности является создание условий для развития межкультурных и межэтнических отношений у пользователей на основе ценностей многонационального российского общества,

Стремясь развивать эффективную систему информационного обслуживания представителей различных национальностей, библиотеки (особенно в поликультурных мегаполисах) уделяют большое внимание развитию многоязычных фондов. В этих целях создаются библиотеки национальных литератур.

Так, в 2006 г. на базе МЦБС им. М.Ю. Лермонтова в Санкт-Петербурге была организована Библиотека национальных литератур при активной поддержке Комитета по культуре города. Ее открытие стало следствием резкого сокращения разделов литературы на языках народов Российской Федерации (кроме русского) в городских библиотеках. В настоящее время фонд библиотеки активно пополняется за счет даров национальнокультурных организаций Санкт-Петербурга (они же помогали в переводах с национальных языков при создании электронного каталога библиотеки), городских и региональных общественных организаций, генеральных консульств. Библиотека и сама приобретает книги. В ее фонде представлена литература на языках более 40 национальностей, проживающих в Санкт-Петербурге. Особая миссия библиотеки - сохранение периодических изданий национально-культурных объединений города. Библиотека разработала иллюстрированную карту путеводитель «Многонациональный Петербург», по материалам которой впоследствии был проведен молодежный квест. Концепция библиотеки предполагает содействие сохранению и развитию этнической культуры различных народов, проживающих в северной столице, взаимодействие с русской, а также формирование взаимоуважения между представителями различных культур [11].

В рамках рассматриваемой темы библиотеки проводят социологические исследования совместно с образовательными учреждениями. Среди недавних следует назвать опрос, проведенный в 2016 г. Свердловской областной межнациональной библиотекой совместно с Уральским государственным педагогическим университетом «Оценка населением состояния межнациональных отношений в Свердловской области» . Изучение было поддержано Министерством культуры Свердловской области. Были опрошены жители всех населенных пунктов Свердловской области. $21 \%$ из них на вопрос: «На Ваш взгляд, кто оказывает наибольшее влияние на формирование толерантного отношения российских граждан к представителям другой национальности?» назвали культурные учреждения (библиотеки, театры, дома культуры и т. д.). Результаты исследования позволили выявить роль культуры в формировании толерантных отношений: она является важнейшим инструментом формирования либерального отношения к другим национальностям. Общий контекст полученных результатов свидетельствует о высокой степени доверия респондентов к библиотекам и о признании их больших возможностей в процессе формирования демократической межэтнической и межкультурной среды [12].

Среди форм работы библиотек с поликультурным населением преобладают массовая и групповая. Прежде всего следует назвать такие формы массовой работы, как:

- фестивали национальных культур и декады языка и культуры, различные этнокультурные акции;

- выставки, посвященные Международному дню толерантности, Международному дню коренных народов и Дню национального единства; 
- творческие встречи с писателями, поэтами, музыкантами;

- литературные и творческие конкурсы.

Групповая работа осуществляется в формах: нений;

- клубов по интересам и творческих объеди-

- кинолекториев, посвященных жизненным укладам различных народов с последующим обсуждением просмотренного фильма;

- тренингов, имеющих целью формирование у населения позитивного отношения к представителям различных культур;

- объединений в библиотеках мигрантов, нуждающихся в информационной поддержке и улучшении знаний русского языка.

Библиотеки участвуют в реализации программ и проектов, направленных на развитие идей толерантности среди исконного населения, которые поддерживаются местными властями. Так, ЦБС Мончегорска (Мурманская область) работает по программе «Главный проект - твоя жизнь», основной целью которой является формирование личности, толерантной к людям других национальностей. Занятия проходят в интерактивной форме: тренинги, решение ситуационных задач, дискуссии. Проект библиотеки-филиала № 7 Оленегорской ЦБС «Ты не один: помощь мигранту» предполагает создание при библиотеке объединения мигрантов, нуждающихся в информационной поддержке и улучшении знаний русского языка [13].

\section{Основные выводы}

1. Опора современной межкультурной деятельности библиотек была заложена в советское время. В значительной степени этому способствовали специальные социологические исследования читательских интересов народов СССР, позволившие сделать выводы о процессе интернационализации чтения, в котором принимали участие массовые библиотеки;

2. Определение межкультурного диалога как процесса, имеющего своей целью открытое и вежливое общение между различными народами и опирающегося на взаимное понимание и уважение, дает нам основание утверждать, что библиотека обладает большим потенциалом для установления этого диалога. Она может способствовать воспитанию навыков межкультурного диалога, а также созданию пространства для его расширения;

3. Современные общедоступные библиотеки нашей страны вовлечены в работу по реализации государственной культурной и национальной политики, развитию межэтнических отношений и гражданского единства российского общества. Она понимается библиотеками как деятельность, направленная на развитие межкультурного диалога - библиотеки становятся центрами межэтнической толерантности и взаимодействия. Ее направления включают в себя различные формы массовой и групповой работы, а также создание многоязычных фондов и многоязычных электронных ресурсов.

\section{Список источников}

1. «Белая книга» по межкультурному диалогу: «Жить вместе в равном достоинстве»: Утверждена министрами иностранных дел стран-членов Совета Европы на 118-й сессии Комитета министров, Страсбург, 7 мая 2008 г. : [пер. с англ. яз.] / Совет Европы. Информационный офис Совета Европы в России. Москва, 2009. 73 с.

2. Добрынина Н.Е. Многонациональная отечественная литература и читательские ориентации // Книга и чтение в зеркале социологии. Москва: Книжная палата, 1990. С. 118-137.

3. Добрынина H.E. Черты духовной общности: Русская художественная литература в чтении многонационального советского читателя. Москва : Книга, 1983. $112 \mathrm{c}$.

4. Основы государственной культурной политики: Утверждены указом Президента Российской Федерации от 24.12.2014 г. [Электронный ресурс]. URL: http://static.kremlin.ru/media/events/ files/41d526a877638a8730eb.pdf (дата обращения: 28.08.2017).

5. Гениева Е.Ю.Библиотека как центр межкультурной коммуникации. Москва : РОССПЭН, 2005. 206 с.

6. Кубряк E.Н.Проблема «критической массы» диссертационных исследований в библиотековедении // Научные и технические б-ки. 2010. № 3. С. 5-16.

7. Гудкова И.Н. Библиотека в культурном пространстве полиэтнического региона: на материалах Республики Бурятия : автореф. дис. ... канд. культурологии : 24.00.01. Чита, 2013. $23 \mathrm{c.}$

8. Сатарова Л.Х. Межкультурные коммуникации в современной библиотечно-информационной среде : автореф. дис. ... канд. пед. наук : 05.25.03. Казань, 2015. $25 \mathrm{c}$.

9. Кокорина С.В. Общедоступные библиотеки в процессе формирования культуры межнационального взаимодействия : автореф. дис. ... канд. пед. наук : 05.25.03. Челябинск, 2015. 26 с.

10. Модельный библиотечный кодекс : для государств - участников СНГ: (новая редакция). Москва : Пашков дом, 2017. 65 с.

11. Соколова Д.К. Библиотека национальных литератур // Формирование толерантности в культурном пространстве города : сборник материалов Межрегиональной конференции городов Северо-Запада России. Архангельск, 2015. С. 42-45.

12. Оценка населением состояния межнациональных отношений в Свердловской области : аналитический отчет о результатах социологического исследования, проведенного по заказу Свердловской областной межнациональной библиотеки и Министерства культуры Свердловской области. Екатеринбург, 2016. 112 с.

13. Информационно-аналитическая справка о деятельности государственных и муниципальных библиотек Мурманской области за 2016 год [Электронный pecypc]. URL: http://www.mgounb.ru/colleagues/ (дата обращения: 08.08.2017). 


\title{
Intercultural Dialogue in Libraries: Theoretical and Practical Aspects
}

\author{
Irene V. Chadnova, \\ Russian State Library, 3/5 Vozdvizhenka Str., Moscow, 119019, Russia \\ E-mail: ChadnovaIV@rsl.ru
}

\begin{abstract}
The modern public libraries of our country are involved in the activities on implementation of the state national and cultural policy. Lately their priority targets have focused on ensuring interethnic harmony in society, conceived by the libraries as the work aimed at the development of intercultural dialogue. The article highlights theoretical and practical aspects of the development of intercultural dialogue in public libraries. The definition of intercultural dialogue as a process aimed at open and polite communication between different peoples, based on mutual understanding and respect, is given. The library activities can promote fostering skills and creating environment for its widening. The author shows that the basics of the modern intercultural library activities was laid by the work of Soviet mass libraries aimed at studying the reading interests of the peoples in the multinational USSR and taking part in their international education. At present, the libraries contribute to the development of titular ethnic groups national cultures and facilitate the process of mutual enrichment of cultures of different peoples of our country in accordance with "The Foundations of the State Cultural Policy". Theoretical basis of intercultural library activities is supplemented by the dissertation research works defended in the different regions of our country. It allows to conclude that in the general structure of the modern library science there has been formed an independent discipline named the "Library Ethnology". To become one of the main translators of the state national and cultural policy the public libraries have developed their own approaches resulted in creating Centers for ethnic interaction and intercultural communication, as well as the Centers of national literatures. As a rule, the main goal of their activities is creation of the conditions for the development of intercultural and interethnic relations among the users, basing on the values of multinational Russian society, the respect of the rights and freedoms of individual, and maintenance of multi-ethnic peace and conciliation in the region.
\end{abstract}

Key words: Intercultural Dialogue, Public Libraries, State Cultural Policy, Center for Ethnic Interaction and National Literatures, Theoretical Basis, Forms of Library Work.

Citation: Chadnova I.V. Intercultural Dialogue in Libraries: Theoretical and Practical Aspects, Bibliotekovedenie [Library and Information Science], 2017, vol. 66, no. 6, pp. 636 -642. DOI: 10.25281/0869608X-2017-66-6-636-642.

\section{References}

1. The White Paper on Intercultural Dialogue, "Living Together as Equals in Dignity”. Moscow, 2009, 73 p. (in Russ.).

2. Dobrynina N.E. Mnogonatsional'naya otechestvennaya literatura i chitatel'skie orientatsii [The Multinational Russian Literature and the Reader's Orientations], Kniga i chtenie v zerkale sotsiologii [The Book and Reading in the Mirror of Sociology]. Moscow, Knizhnaya Palata Publ., 1990, pp. 118-137.

3. Dobrynina N.E. Cherty dukhovnoi obshchnosti: Russkaya khudozhestvennaya literatura $v$ chtenii mnogonatsional'nogo sovetskogo chitatelya [The Features of Spiritual Commonality: The Russian Fiction Literature in the Reading of a Multinational Soviet Reader]. Moscow, Kniga Publ., 1983, 112 p.

4. Osnovy gosudarstvennoi kul'turnoi politiki: Utverzhdeny ukazom Prezidenta Rossiiskoi Federatsii ot 24.12.2014 g. [Foundations of the State Cultural Policy: Approved by the Decree of the President of the Russian Federation Dated 24.12.2014]. Available at: http://static.kremlin.ru/media/events/

files/41d526a877638a8730eb.pdf (accessed 28.08.2017).

5. Genieva E.Yu. Biblioteka kak tsentr mezhkul'turnoi kommunikatsii [Library as a Center of Intercultural Communication]. Moscow, ROSSPEN Publ., 2005, $206 \mathrm{p}$.

6. Kubryak E.N. Problema "kriticheskoi massy" dissertatsionnykh issledovanii v bibliotekovedenii [The Problem of "Critical Mass" of Dissertation Studies in Library Science], Nauchnye i tekhnicheskie b-ki [Scientific and Technical Libraries], 2010, no. 3, pp. 5-16.

7. Gudkova I.N. Biblioteka v kul'turnom prostranstve polietnicheskogo regiona: na materialakh Respubliki Buryatiya [Libraries in the Cultural Space of a Polyethnic Region: On the Materials of the Republic of Buryatia], Cand. cult. diss. Abstr.: 24.00.01. Chita, 2013, 23 p.

8. Satarova L.Kh. Mezhkul'turnye kommunikatsii $v$ sovremennoi bibliotechno-informatsionnoi srede [The Intercultural Communications in the Modern Library and Information Environment], Cand. ped. sci. diss. Abstr.: 05.25.03. Kazan, 2015, 25 p. 
9. Kokorina S.V. Obshchedostupnye biblioteki v pro tsesse formirovaniya kul'tury mezhnatsional'nogo vzaimodeistviya [Public Libraries in the Process of Formation of the Culture of Interethnic Cooperation], Cand. ped. sci. diss. Abstr.: 05.25.03. Chelyabinsk, 2015, $26 \mathrm{p}$.

10. Model'nyi bibliotechnyi kodeks: dlya gosudarstv uchastnikov SNG: (novaya redaktsiya) [The Model Library Code: For Member States of the CIS (New Revision)]. Moscow, Pashkov Dom Publ., 2017, 65 p.

11. Sokolova D.K. Biblioteka natsional'nykh literatur [The Library of Ethnic Literatures], Formirovanie tolerantnostiv kul'turnom prostranstve goroda: sbornik materialov Mezhregional'noi konferentsii gorodov Severo-Zapada Rossii [Proceedings of the Interregional Conference of the North-Western Cities of Russia "Forming Tolerance in the City's Cultural Space"]. Arkhangelsk, 2015, pp. 42-45.
12. Otsenka naseleniem sostoyaniya mezhnatsional'nykh otnoshenii $v$ Sverdlovskoi oblasti: analiticheskii otchet o rezul'tatakh sotsiologicheskogo issledovaniya, provedennogo po zakazu Sverdlovskoi oblastnoi mezhnatsional'noi biblioteki i Ministerstva kul'tury Sverdlovskoi oblasti [The Public Assessment of Interethnic Relations in the Sverdlovsk Region: The Analytical Report on the Results of the Sociological Research, Commissioned by the Sverdlovsk Regional Interethnic Library and the Ministry of Culture of the Sverdlovsk Region]. Yekaterinburg, 2016, $112 \mathrm{p}$.

13. Informatsionno-analiticheskaya spravka o deyatel'nosti gosudarstvennykh i munitsipal'nykh bibliotek Murmanskoi oblasti za 2016 god [The Information and Analytical Report on the Activities of State and Municipal Libraries in the Murmansk Region for 2016]. Available at: http://www.mgounb. $\mathrm{ru} /$ colleagues/ (accessed 08.08.2017).

\section{Анонс}

\section{Международная научно-практическая конференция "Румянцевские чтения - 2018" \\ Тема: «Библиотеки и музеи как культурные и научные центры: историческая ретроспектива и взгляд в будущее \\ (к 190-летию со времени основания Румянцевского музея)»}

$$
\text { 24-25 апреля } 2018 \text { г. }
$$

Цель конференции: привлечь внимание к вопросам сохранения и изучения мирового культурного наследия и национальных ценностей, а также к проблемам функционирования библиотек на современном историческом этапе, способствовать поиску путей инновационного развития, расширению сотрудничества между учреждениями культуры, образования, науки и межкультурному взаимодействию.

Конференция состоится в форме пленарного заседания, заседаний секций и круглых столов. В рамках «Румянцевских чтений» планируется провести семинар «Наука в библиотеке: содержание, организация, представление результатов» из цикла научно-практических семинаров РГБ «Роль науки в развитии библиотек (теоретические и практические аспекты)», организовать работу круглых столов: «Библиотеки в сохранении и развитии историко-культурного наследия стран СНГ», «ПЦПИ библиотек как центры формирования информационной и правовой культуры граждан (к 20 -летию образования публичных центров правовой информации)», «Стандартизация в области библиотечно-информационного обслуживания: обсуждение проекта стандарта» и др.

Информационная поддержка: журналы «Библиотековедение», «Обсерватория культуры», «Вестник Библиотечной Ассамблеи Евразии», издательство «Пашков дом» .

Срок подачи материалов: до 01 февраля 2018 года.

Статьи направляются по электронной почте: rum@rsl.ru

Дополнительная информация и регистрация участников: http://rumchten.rsl.ru Место проведения: Москва, ул. Воздвиженка, д. $3 / 5$ (Российская государственная библиотека).

Контакты:

E-mail: IvanovaEA@rsl.ru

Тел.: +7 (499) 557-04-70, доб. 22-52 